\title{
Article
}

\section{Influence of opposition team formation on physical and skill-related performance in a professional soccer team}

Carling, C.

Available at http://clok.uclan.ac.uk/12263/

Carling, C. ORCID: 0000-0002-7456-3493 (2011) Influence of opposition team formation on physical and skill-related performance in a professional soccer team. European Journal of Sport Science, 11 (3). pp. 155-164. ISSN 1746-1391

It is advisable to refer to the publisher's version if you intend to cite from the work. http://dx.doi.org/10.1080/17461391.2010.499972

For more information about UCLan's research in this area go to http://www.uclan.ac.uk/researchgroups/ and search for <name of research Group>.

For information about Research generally at UCLan please go to http://www.uclan.ac.uk/research/

All outputs in CLoK are protected by Intellectual Property Rights law, including Copyright law. Copyright, IPR and Moral Rights for the works on this site are retained by the individual authors and/or other copyright owners. Terms and conditions for use of this material are defined in the policies page.

\section{CLoK}

Central Lancashire online Knowledge www.clok.uclan.ac.uk

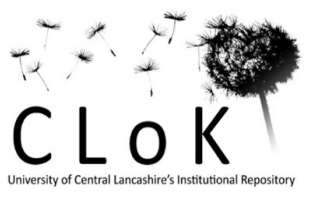


This is a pre-proof corrected manuscript, as accepted for publication, of an article published by Taylor \& Francis in European Journal of Sport Science on $9^{\text {th }}$ May 2011. The final publication is available at: http://www.tandfonline.com/doi/abs/10.1080/17461391.2010.499972?journalCode=tejs20 \#.VbNNSvlVhBc

\section{PLEASE REFER TO THE PUBLISHED VERSION FOR CITING PURPOSES}

Influence of opposition team formation on physical and skill-related performance in a professional soccer team.

Authors: ${ }^{1}$ Christopher Carling

Institutions:

${ }^{1}$ LOSC Football Club, EMSP, Domain de Luchin, Camphin-en-Pévèle, 59780, France.

Correspondance: LOSC Football Club, EMSP, Domain de Luchin, Camphin-en-Pévèle, 59780, France.

Phone: 00.33.1.4891 0793

Fax: 00.33.1.4891 0793

Email: chris.carling@free.fr

Running head: Physical performance in professional soccer 


\title{
The influence of opposition team formation on physical and skill-related performance in a professional soccer team.
}

Running head: Physical and skill performance in elite soccer

\begin{abstract}
This study examined the influence of opposition team formation on physical and skillrelated performance in a professional soccer team. Performance in forty-five French League 1 matches played over three competitive seasons (2007-08, 2008-09, and 2009-10) was analysed using multi-camera computerised tracking. Players $(n=21)$ in the reference team (using a 4-3-3/4-5-1 formation) were analysed in matches against three opposition team formations: 4-4-2 (11 games), 4-3-3/4-5-1 (16 games) and 4-2-3-1 (18 games). Performance was compared for defending and midfield units as a whole and individually across four positions: fullbacks, central-defenders and central- and wide-midfielders. Collectively, players covered a greater total distance $(\mathrm{p}<0.05)$ and distance in low/moderate-intensity running $(0-14.3 \mathrm{~km} / \mathrm{h})(\mathrm{p}<0.05)$ in matches against a $4-2-3-1$ compared to a 4-4-2 formation. Distance covered in high-intensity $(14.4-19.7 \mathrm{~km} / \mathrm{h})$ and very high-intensity running $(\geq 19.8 \mathrm{~km} / \mathrm{h})$ was not affected by opposition formation. In contrast, players covered more distance in total high-intensity performance $(\geq 14.4 \mathrm{~km} / \mathrm{h})$ when the reference team was in possession against a 4-4-2 compared to a 4-2-3-1 formation $(\mathrm{p}<0.05)$ while more distance was run at these speeds when the reference team was out of possession against a 4-2-3-1 ( $\mathrm{p}<0.01)$ and a 4-3-3 $(\mathrm{p}<0.05)$ compared to a 4-4-2 formation. Players ran less distance at low/moderate intensities in the second- versus firsthalf of matches against all three formations $(\mathrm{p}<0.01$ to $\mathrm{p}<0.05)$ whereas total distance and high-intensity performance was unaffected. None of the measures of physical performance across the individual playing positions were affected by opposition team formation. Skillrelated performance varied according to opposition formation: players as a whole performed more passes versus a 4-4-2 than a 4-2-3-1 ( $<<0.01)$, ground and aerial duels versus a 4-2-3-1 compared to a 4-4-2 (both $\mathrm{p}<0.01$ ); 1-touch passes versus a 4-2-3-1 compared to a 4-4-2 (p<0.01) and a 4-3-3/4-5-1 ( $<<0.05)$. The mean number of touches per possession was highest versus a 4-4-2 compared to a 4-3-3/4-5-1 $(\mathrm{p}<0.01)$ and a 4-2-31 ( $\mathrm{p}<0.01)$. While skill-related performance across the four individual playing positions was generally unaffected by opposition team formation, mean pass length was greater in central-midfielders against a 4-4-2 compared to 4-3-3/4-5-1 ( $\mathrm{p}<0.05)$ and 4-2-3-1 ( $<<0.01)$ formations. In general, these findings suggest that physical performance in the reference team was not greatly affected by opposition team formation. In contrast, skill-related demands varied substantially according to opponent formation and may have consequences for tactical and technical preparation and team selection policies.
\end{abstract}

Key terms: playing system, football, motion-analysis, technical performance 


\section{Introduction}

A thorough understanding of the physical demands of professional soccer is required so that optimal training and preparation strategies can be constructed to respond to the demands of match-play. Recently, advanced computerised motion-analyses of performance in contemporary match-play have provided comprehensive insights into the activity profiles of professional soccer players and the physical requirements of competition (Drust, Atkinson, \& Reilly 2007). Motion-analyses have also been used to investigate a myriad of variables that affect the physical performance profile of players in competition. These include the positional roles of players (Barros et al., 2007; Di Salvo et al., 2007), cultural differences (Rienzi, Drust, Reilly, Carter \& Martin, 2000), standard of play (Mohr, Krustrup \& Bangsbo, 2003), team quality (Di Salvo, Gregson, Atkinson, Tordoff, \& Drust, 2009; Rampinini, Coutts, Castagna, Sassi, \& Impellizzeri, 2007), match congestion (Odetoyinbo, Wooster, \& Lane, 2007), score line (Bloomfield, Polman, \& O'Donoghue, 2004), player dismissals (Carling \& Bloomfield, 2010), substitutes (Carling, Espié, Le Gall, Bloomfield \& Jullien, 2010) and the physical condition (Krustrup et al., 2003) and age (Pereira Da Silva, Kirkendall, \& Leite De Barros Neto, 2007) of players.

There is also speculation that the physical efforts of players in match-play are influenced by team formation (Bradley et al., 2009; Carling, Bloomfield, Nelsen, \& Reilly, 2008; Drust et al., 2007). Indeed, the choice of team formation should take into account individual physical abilities such as endurance and speed (Bauer, 1993). Furthermore, the interaction between physical, tactical and technical skills should also be considered when evaluating performance according to team formation (Carling, Williams \& Reilly, 2005). Yet to date, only one preliminary study using a relatively small sample size (19 matches) has examined the effects of team formation on physical and skill-related (tactical and technical) performance (Bradley et al., 2009). Performance in teams adopting 
4-4-2, 4-3-3 and 4-5-1 formations respectively was compared. The results showed that teams using a 4-4-2 performed more high-intensity running and passes than those using a 4-5-1 formation. Furthermore, no study has investigated the direct influence of opposition team formation on physical and skill-related performance in a reference soccer team. Related research in professional Italian soccer has shown that physical performance in a reference team was directly related to the physical activity completed by opponent teams (Rampinini et al., 2007). However, no information was provided as to the possible influence on findings of the respective team formations used by opponents.

Further research using match-analyses into the influence of opposition team formation on physical and skill-related performance is therefore warranted. This information may have implications for aiding team selection and optimising physical and tactical preparation strategies for matches against different formations. It may also be useful in identifying a link between match-related decrements in physical performance and opposition team formation. Declines in physical performance in competition can occur directly after intense periods of activity, and during the later stages of games suggesting temporary and permanent fatigue (Mohr, Krustrup, \& Bangsbo, 2005). The identification of reduced physical performance in competition that occurs specifically against certain team formations would be beneficial in informing strategies to aid teams to maintain performance throughout such matches.

Consequently, the aim of this study in professional soccer match-play was to investigate the effect of opposition team formation on physical activity profiles and skillrelated (tactical and technical) performance in a reference team.

\section{Methods}

Participants and match sample 
With ethics approval from the internal review board of the sampled football club, physical, tactical and technical demands of match-play were analysed for outfield soccer players in a professional soccer team that competed in the French League 1 division (highest standard in French soccer). To ensure player confidentiality, all performance data were anonymised before analysis.

A total of 45 official games over three seasons (2007/2008: N=15, 2008/2009: $\mathrm{N}=18,2009 / 2010: \mathrm{N}=12$ ) in which players completed the entire match were included for analysis. Performance in the reference team was analysed in matches against three team formations commonly used in professional soccer: 4-4-2 (11 games, 9 teams), 4-3-3/4-5-1 (16 games, 12 teams) and 4-2-3-1 (18 games, 13 teams). The reference team recorded two top-ten finishes $\left(9^{\text {th }}\right.$ and $\left.5^{\text {th }}\right)$ in the first two seasons and was placed $5^{\text {th }}$ at the moment the final game was analysed in the current season. The standard of the sample of opponent teams analysed for each formation was: 4-4-2 = 4 top-ten and 7 bottom-nine placed teams; 4-3-3/4-5-1 = 9 top-ten and 7 bottom-nine placed teams, and; 4-2-3-1 = 9 top-ten and 9 bottom-nine placed teams. The interaction between opposition standard (based on League position) and team formation was verified for the performance measures. Two- and threeway ANOVA's showed no significant interactions between factors $(p>0.05)$ thereby indicating that the standard of opposition did not confound the results.

To determine opponent team formations, two UEFA-qualified coaches (one from the reference club's coaching staff and one independent observer) observed video recordings of the sampled games. These observers subjectively determined team formations at the start of games and also verified that the formations were consistent throughout the games. Games in which a dismissal occurred were not included for analysis. Teams that played a 4-3-3 formation were combined with those using a 4-5-1 system. Distinction between these two systems was deemed to be difficult by the 
observers as teams often played a 4-3-3 when in possession and reverted to a 4-5-1 when out of possession. The reference team was generally organised in the 4-3-3/4-5-1 format and only games in which this formation was used were included for analysis.

Altogether, 21 players participated with a median of 15.5 matches (in which the full 90-minutes were played) per player (range=1-38). This sample led to a total of 297 observations of match performance. Of this total, the number of observations for each position was respectively: fullbacks: $\mathrm{N}=82$, central-defenders: $\mathrm{N}=80$, central-midfielders: $\mathrm{N}=78$ and wide-midfielders: $\mathrm{N}=57$. Forward players were excluded due to a low number of observations in both the reference and opposition teams.

\section{Data collection procedures and measures of competitive performance}

A computerised player tracking system (AMISCO Pro ${ }^{\circledR}$, Sport-Universal Process, Nice, France) was used to characterise activity profiles in the reference team. This multiplecamera system tracks the movements of every player at a sampling rate of $10 \mathrm{~Hz}$ over the course of matches and provides data on the distances covered at different movement speeds (Carling, Williams \& Reilly, 2005). A trained operator simultaneously codes technical actions involving the ball according to a pre-defined classification. The workings, accuracy and reliability of the AMISCO Pro ${ }^{\circledR}$ system in measuring player movement and coding match-specific events in elite soccer competition have been described in more detail elsewhere (Di Salvo et al. 2007; Carling et al., 2008; Zubillaga, Gorospe, Hernadez-Mendo, Blanco-Villanesor, 2008; Randers et al., 2010).

Physical and technical performance was determined automatically from the raw data files by computerised analysis of player movements and actions using match-analysis software (AMISCO Viewer ${ }^{\circledR}$, Sport-Universal Process, Nice, France). To avoid the potential effect of variations in duration across games, information obtained in injury time 
or extra time was not included for analysis. Performance data for each game were therefore analysed over 90-minutes (two halves of 45-minutes).

The performance measures selected for the analyses were classified into three categories: 1) Physical performance: total distance covered and distance covered in three categories of movement speed (Bradley et al. 2009): 0.0-14.3 km/h (low/moderateintensity); 14.4-19.7 km/h (high-intensity); $\geq 19.8$ km/h (very high-intensity). Total highintensity performance was defined as movement performed at speeds $\geq 14.4 \mathrm{~km} / \mathrm{h}$ (highintensity and very high-intensity running combined). The distance covered in total highintensity performance was measured for players when in individual possession of the ball and when their team was in (attacking play) and out (defensive play) of possession. In addition, both the mean time spent in recovery between actions performed in the total high-intensity performance category and the mean length of these efforts were calculated.

2) Declines in physical performance: all measures of physical performance were compared across match halves. End-game performance was also analysed by comparing the percentage change in distance covered in total high-intensity performance. For this, the distance run in the final 15-minute period was compared to that for the first 15-minute period and the mean of other 15-minute periods (mean of all periods minus final 15minute period).

3) Skill-related performance measures defined and calculated in the $\mathrm{AMISCO}^{\circledR}$ Pro system included: frequency of passes and forward passes, mean length of passes, percentage of passes played with 1-touch, frequency of ball possessions, mean time and number of touches per possession and frequency of ground and aerial duels. Finally, measures of the total time the ball was in play and the percentage of time spent in possession were measured across games for the team as a whole. 


\section{Statistical Analyses}

All statistical analyses were conducted using SPSS for Windows Version 14.0 (SPSS Inc., Chicago, IL, USA). Data are presented as means and standard deviations unless otherwise stated. Before using parametric statistical test procedures, the normality of the data was verified. Two-way analysis of variance (ANOVA) was used to test for differences in means for all players in performance measures against the three opposition formations and to examine the interaction between playing position and opposition formation. To investigate declines in performance, a three-way ANOVA was performed on each category of physical performance to examine the interaction between performance across match halves, opposition formation and playing position. To study end-game decrements in performance, a two-way ANOVA was used to compare the interaction between percentage decline in physical performance (efforts in end 15-minute period compared to first and mean 15-minute periods), opposition formation and playing position. Follow-up univariate analyses using Bonferroni-corrected pair wise comparisons were used where appropriate.

Effect sizes for statistical differences were also determined. Effect size values of 0.20-0.49, 0.50-0.79 and 0.8 and above were considered to represent small, medium and large differences, respectively (Cohen, 1988).

\section{Results}

\section{Physical performance}

Data on each category of performance against the three opposition team formations are presented in Table 1. The total distance run for players in all positions combined varied when performing against the three opposition team formations $(\mathrm{P}=0.026)$. Players 
covered greater total distances against a 4-2-3-1 ( $\mathrm{p}<0.05, \mathrm{ES}=0.32)$ compared to a 4-4-2 formation.

Table 1 about here.

The distance covered in low/moderate-intensity running also varied when competing against the three opposition team formations $(\mathrm{P}=0.007)$. Players ran more distance at low/moderate intensities against a 4-2-3-1 compared to a 4-4-2 formation $(\mathrm{p}<0.01, \mathrm{ES}=0.49)$.

The analysis of total high-intensity running performance by all players when their team was in possession varied when competing against the three formations $(\mathrm{P}=0.032)$. Players covered more distance when their team was in possession against a 4-4-2 compared to a 4-2-3-1 formation $(\mathrm{p}<0.05$, ES=0.30). Similarly, the distance covered in total high-intensity performance when out of possession differed $(\mathrm{P}=0.004)$ according to opposition team formation. Players ran significantly more distance against a 4-2-3-1 $(\mathrm{p}<0.01, \mathrm{ES}=0.40)$ and a 4-3-3 $(\mathrm{p}<0.05, \mathrm{ES}=0.37)$ compared to a 4-4-2 formation.

No differences were observed in matches against the three opposition team formations in: distance covered in high-intensity $(\mathrm{P}=0.476)$ and very high-intensity movement $(\mathrm{P}=0.411)$; total high-intensity performance: mean recovery time between $(\mathrm{P}=0.230)$ and mean length $(\mathrm{P}=0.667)$ of actions; distance run in individual ball possession $(\mathrm{P}=0.307)$.

Finally, no significant interaction was observed in any of the measures of physical performance for efforts across the individual playing positions against the three opposition team formations. 
Declines in performance

The formation used by opponent teams affected the distance covered by the reference team in low/moderate-intensity running across match halves $(\mathrm{p}=0.005)$. Players in all positions combined performed less running at low/moderate intensities in the second- versus the first-half of matches against the three formations: 4-4-2: $1^{\text {st }}$ Half $=4267 \pm 201 \quad$ vs. $\quad 2^{\text {nd }} \quad$ Half $=4046 \pm 191, \quad$ p $<0.01, \quad E S=1.20 ; \quad 4-3-3 / 4-5-1: \quad 1^{\text {st }}$ Half $=4281 \pm 191$ vs. $2^{\text {nd }}$ Half $=4142 \pm 190, p<0.05, E S=0.71 ; 4-2-3-1: 1^{\text {st }} H a l f=4280 \pm 198$ vs $2^{\text {nd }}$ Half $=4199 \pm 220, p<0.05, E S=0.40$. The total distance run and distance covered at other movement speeds across match halves were unaffected by opposition team formation. Similarly, total high-intensity performance across match halves (Table 2: recovery time between and length of actions) and the percentage decrement during the final 15-minute period of matches) was unaffected by opposition team formation. Finally, performance in none of the physical performance measures across game halves within the four playing positions was affected by opposition team formations.

Table 2 about here.

\section{Skill-related performance}

A significant difference when playing against the three formations was observed for players in all positions combined in the following skill-related performance variables (Table 3): Passing frequency $(\mathrm{p}=0.007)$ with players performing more passes versus a 4-42 than a 4-2-3-1 $(\mathrm{p}<0.01$, ES=0.50); mean number of ball touches per possession $(\mathrm{p}=0.003)$ with players taking more touches versus a 4-4-2 compared to a $4-3-3 / 4-5-1$ $(\mathrm{p}<0.01, \mathrm{ES}=0.67)$ and a 4-2-3-1 $(\mathrm{p}<0.01, \mathrm{ES}=0.63)$; frequency of ground duels $(\mathrm{p}=0.022)$ with players performing more duels versus a 4-2-3-1 compared to a 4-4-2 $(\mathrm{p}<0.01$, 
$\mathrm{ES}=0.57$ ); frequency of aerial duels $(\mathrm{p}=0.004)$ with players performing more duels versus a 4-2-3-1 than a 4-4-2 $(\mathrm{p}<0.01, \mathrm{ES}=0.56)$; percentage of passes played with 1-touch $(\mathrm{p}<0.001)$ with players performing more passes versus a 4-2-3-1 compared to a 4-4-2 $(\mathrm{p}<0.01, E S=0.59)$ and 4-3-3/4-5-1 $\quad(\mathrm{p}<0.05, \mathrm{ES}=0.44)$ formation. No difference was observed in the mean length of passes against the three formations for players in all positions combined $(\mathrm{p}=0.884)$. While skill-related performance was generally unaffected across playing positions against the different team formations, mean pass length varied $(\mathrm{p}=0.018)$ as this was greater in central-midfielders against a 4-4-2 compared to a 4-3-3/4$5-1(\mathrm{p}<0.05, \mathrm{ES}=0.50)$ and 4-2-3-1 $(\mathrm{p}<0.01, \mathrm{ES}=0.57)$.

The time the ball was in play $(4-4-2=50 \mathrm{mins} 40 \mathrm{~s}$ vs. $4-3-3 / 4-5-1=49 \mathrm{mins} 29 \mathrm{~s}$ vs. $4321=49$ mins $0 \mathrm{~s}, \mathrm{p}=0.419)$ was similar against all formations. In contrast, the percentage of time spent in possession by the reference team varied against the three formations (4-4$2=55 \%$ vs. $4-3-3 / 4-5-1=52.4 \%$ vs. $4-2-3-1=50.3 \%, p=0.035)$ with more possession observed against a 4-4-2 compared to a 4-2-3-1 ( $p<0.05, E S=0.67)$ formation.

Table 3 about here.

\section{Discussion}

In this study, a detailed investigation of the physical and skill-related activity profiles in a professional soccer team when competing against three common team formations was conducted. The major finding is that certain aspects of physical and skill-related performance in defensive and midfield units as a whole are affected when competing against different opposition team formations. In contrast, opposition team formation generally did not influence physical and skill-related performance across four individual 
playing positions. Similarly, physical performance across halves and towards the end of matches was generally unaffected by opposition team formation.

The total distance covered in elite soccer match-play provides a global indication of the intensity of exercise. In general, contemporary outfield male professional soccer players cover on average $9-13 \mathrm{~km}$ per match (Stølen, Chamari, Castagna, \& Wisløff, 2005). In this study, players across the defensive and midfield positions ran distances within this range. However, the overall distance covered and distance covered at low/moderate intensities by players as a whole (attacking and midfield roles combined) was influenced by opposition formation and notably increased when performing against a 4-2-3-1 formation. The small effect sizes observed for these data may indicate however, that these differences though statistically significant, may have limited practical relevance (Di Salvo et al., 2009). Nevertheless, this finding tends to confirm previous speculation (Carling et al., 2008; Drust et al., 2007) that opposition team formations govern player efforts as these determined the overall physical demands of elite soccer match-play. However, opposition team formation did not influence physical performance when the effect of individual playing position was taken into account. These results suggest that while the team as a whole may have needed to adjust its efforts against different team formations, the individual demands across playing positions did not vary according to opposition formation. Caution is needed when interpreting these findings however as information on forward players was not available and further research with the inclusion of these players is warranted.

The analysis of high-intensity running activity (distances covered, mean recovery times and length of actions) showed that performance did not vary for all players or across individual playing positions in the reference team when competing against the three opposition team formations. The efforts made at high-intensities are often critical to the 
outcome of matches (Di Salvo et al., 2009) yet the present results suggest that opposition formation did not affect the overall demands placed on players in this aspect of play. In contrast, distance covered in total high-intensity performance (movement $\geq 14.4 \mathrm{~km} / \mathrm{h}$ ) varied substantially according to team ball possession (Table 1). Players in all positions combined covered more distance when their team had possession against a 4-4-2 compared to a 4-2-3-1 formation. In games against the latter and the 4-3-3/4-5-1 formations, players ran more when their team was out of possession than against the 4-4-2 formation. A related study in Premier League soccer players also showed that distance in high-intensity movement according to ball possession varied significantly across teams using different formations (Bradley et al., 2009). The present results tend to support this observation and suggest a link with the attacking and defensive tactical demands imposed by opposition formations. Indeed, the significant variation in the percentage of time in ball possession in the reference team against three opposition formations is noteworthy as the team had substantially less possession (-4.7\%) in games against a 4-2-3-1 compared to a 4-4-2 formation. Players may therefore have had to cover greater distances in defensive play (e.g., to regain possession) in matches against a 4-2-3-1 formation. These results imply that the evaluation of performance in high-intensity running both in and out of possession should take into account opposition team formation and the time spent in ball possession.

Overall, the total distance covered by all players dropped significantly in the secondhalf of matches when opposition formation was not taken into account $(\mathrm{p}<0.001)$. This fall in overall performance between halves is commonly observed in elite-standard soccer (Reilly, Drust, \& Clarke, 2008). In contrast, the physical efforts across match halves (total distance run and that covered at high- and very-high-intensities, and recovery time between and length of actions in total high-intensity performance) were unaffected when 
opposition formation was considered. Similarly, no decrement in total high-intensity performance during the final 15-minute period of matches was reported irrespective of opposition formation. In addition, opposition team formation did not influence any decline in physical performance across individual playing positions. Indeed, the aim of any team formation is to ensure optimal team organisation in order to best utilise the physical capacities of players and reduce the efforts required to gain and use possession (Doucet, 2007). While the distance covered in low/moderate-intensity movement declined significantly in the second-half of games, this reduction was common to matches against all formations. These results as a whole generally imply that game-related decrements in physical performance in the present team were not influenced by opposition formation.

The choice of team formation is tactically important as the designation of player positions and roles aims to give the team the best options for manoeuvring in both attacking and defensive play (Bangsbo \& Peterson, 2000). In this study, the analysis of skill-related performance showed that the frequency of several game actions was heavily influenced by opposition team formation although this was generally not the case for the individual playing positions. Once again, the moderate effect sizes observed for these differences may, to a certain extent, limit practical relevance. Nevertheless, when competing against a 4-4-2, defending and midfield players as a whole performed more passes and more ball touches per possession versus a 4-2-3-1 formation. These results again suggest a link with the time spent in ball possession as the reference team dominated possession in games versus a 4-4-2 formation. In contrast, players performed considerably more duels (aerial and ground) and 1-touch passes against a 4-2-3-1 compared to a 4-4-2 formation. In addition to time spent in ball possession, these findings may be linked to the specific tactical role of opposition players with respect to certain formations as well as the technical ability of individuals across teams (Carling, Williams \& Reilly, 2005). 
Nevertheless, the present findings are noteworthy and may have consequences for tactical preparation and team selection based on opposition formation. For example, the higher frequency of 1-touch passes against teams using a 4-2-3-1 formation suggests that players in the reference team could have benefited from performing 1-touch passing drills in preparation for matches against this particular formation.

The limitations of this study were the relatively low number of players within certain positional roles and the non-representation of all playing positions especially centreforwards. Also, the process of determining team formations and ensuring that these were consistent throughout games relied solely on the subjective assessment of observers. A future study is warranted to attempt to determine an objective and reliable means for assessing the choice of team formation and when changes occur. Finally, comparative information on physical and skill-related performance in matches against other team formations (e.g., 3-5-2 or 4-4-1-1) used in professional soccer, was not available.

In summary, the present study provided a comprehensive evaluation of physical and skill-related activity profiles in a professional soccer team when competing against three different team formations. These findings have broadened the understanding of one of the many factors that can impact on physical performance in professional soccer match-play. A major aim of motion-analyses of physical performance is to aid coaches and practitioners in making objective decisions for structuring the conditioning elements of training and subsequent match preparation (Bradley et al. 2009; Carling, 2010). However, the present results on the whole do not lend support to the implementation of specific physical conditioning regimes to prepare for matches against any of the three common formations adopted by the present opposition teams. In contrast, skill-related demands varied substantially for the reference team as a whole when competing against the three 
opposition formations and these differences may have consequences for tactical and technical match preparation strategies and team selection policies.

\section{References}

Bangsbo, J., \& Peterson, B. (2000). Soccer Systems \& Strategies. Champaign, IL, USA: Human Kinetics.

Barros, R.M.L., Misuta, M.S., Menezes, R.P., Figueroa, P.J., Moura, F.A., Cunha, S.A., Anido, R., \& Leite, N.J. (2007). Analysis of the distances covered by first division Brazilian soccer players obtained with an automatic tracking method. Journal of Sports Science and Medicine. 6, 233-242.

Bauer, G. (1993). Soccer Techniques, Tactics \& Teamwork. Sterling Publishing Company, New York, USA: Sterling Publishing Company.

Bloomfield, J.R., Polman, R.C.J., \& O'Donoghue, P.G. (2004). Effects of score-line on match performance in FA Premier League Soccer. Journal of Sports Sciences, 23, 192193.

Bradley, P., Dodds, A., Peart, D., Paul, D., Gomez, A, Archer, D., Krustrup, P., \& Roberts, J. (2009). The effect of formation in high-intensity activity and technical performance in elite soccer players. British Journal of Sports Medicine, 43: e2, 16.

Bradley, P.S., Sheldon, W., Wooster, B., Olsen, P., Boanas P., \& Krustrup, P. (2009). High-intensity running in FA Premier League soccer matches. Journal of Sports Sciences, 27, 159-168.

Carling, C., Williams, A.M., \& Reilly, T. (2005). The Handbook of Soccer Match Analysis. Abingdon, UK: Routledge. 
Carling, C., Bloomfield, J., Nelsen, L., \& Reilly, T. (2008). The role of motion analysis in elite soccer: Contemporary performance measurement techniques and work-rate data. Sports Medicine, 38, 839-862.

Carling, C. (2010). Analysis of physical activity profiles when running with the ball in a professional soccer team. Journal of Sports Sciences, 28, 319-328.

Carling, C., \& Bloomfield, J. (2010). The effect of an early dismissal on player work-rate in a professional soccer match. Journal of Science and Medicine in Sport, 13, 126-128.

Carling, C., Espié, V., Le Gall, F., Bloomfield, J., \& Jullien, H. (2010) Work-rate of substitutes in elite soccer: A preliminary study. Journal of Science and Medicine in Sport, $13,253-255$.

Cohen, J. (1988). Statistical power analysis for the behavioural sciences. 2nd ed. Hillsdale, NJ: Lawrence Erlbaum.

Di Salvo, V., Baron, R., Tschan, H., Calderon Montero, F.J., Bachl, N., \& Pigozzi, F. (2007). Performance characteristics according to playing position in elite soccer. International Journal of Sports Medicine, 28, 222-227.

Di Salvo, V., Gregson, W., Atkinson, G., Tordoff, P., \& Drust, B. (2009). Analysis of high intensity activity in Premier League soccer. International Journal of Sports Medicine, 30, 205-212.

Doucet, C. (2002). Football: Entraînement tactique. Paris, France: Editions Amphora.

Drust, B., Atkinson, G., \& Reilly, T. (2007). Future perspectives in the evaluation of the physiological demands of soccer. Sports Medicine, 37, 783-780.

Krustrup, P., Mohr, M., Amstrup, T., Rysgaard, T., Johansen, J., Steensberg, A., Pedersen P.K., \& Bangsbo, J. (2003). The yo-yo intermittent recovery test: physiological response, reliability, and validity. Medicine \& Science in Sports \& Exercise, 35, 697-705. 
Mohr, M., Krustrup, P., \& Bangsbo, J. (2003). Match performance of high-standard soccer players with special reference to development of fatigue. Journal of Sports Sciences, 21, $519-528$.

Mohr, M., Krustrup, P., \& Bangsbo, J. (2005). Fatigue in soccer: A brief review. Journal of Sports Sciences, 23, 593-599.

Odetoyinbo, K., Wooster, B., \& Lane, A. (2008) The effect of a succession of matches on the activity profiles of professional soccer players. In: T. Reilly, \& Korkusuz, F, (Eds.) Science \& Football VI, (pp. 105-111). Abingdon, UK.

Pereira Da Silva, N., Kirkendall, D.T., \& Leite De Barros Neto, T. (2007). Movement patterns in elite Brazilian youth soccer. Journal of Sports Medicine \& Physical Fitness, $47,270-275$.

Rampinini, E., Coutts, A.J., Castagna, C., Sassi, R., \& Impellizzeri, F.M. (2007). Variation in top-level soccer match performance. International Journal of Sports Medicine, 28, 1018-1024.

Rampinini, E., Impellizzeri, F.M., Castagna, C., Coutts, A.J., \& Wisløff, U. (2009). Technical performance during soccer matches of the Italian Serie A league: Effect of fatigue and competitive level. Journal of Science and Medicine in Sport, 12, 227-233.

Randers, M.B., Mujika, I, Hewitt, A., Santisteban, J., Bischoff, R., Solano, R., Zubillaga, A., Peltola, E., Krustrup, P., \& Mohr, M. (2010). Application of four different football match analysis systems: A comparative study. Journal of Sports Sciences, 28, 171-182. Reilly, T., Drust, B., \& Clarke, N. (2008). Muscle fatigue during football match-play. Sports Medicine, 38, 357-367.

Rienzi, E., Drust, B., Reilly, T., Carter, J.E., Martin, A. (2000). Investigation of anthropometric and work-rate profiles of elite South American international soccer players. Journal Sports Medicine Physical Fitness, 40, 162-169. 
Stølen, T., Chamari, K., Castagna, C., \& Wisløff, U. (2005). Physiology of soccer: an update. Sports Medicine, 35, 501-536.

Zubillaga, A., Gorospe, G., Hernadez-Mendo, A., \& Blanco-Villanesor, A. (2008). Comparative analysis of the high-intensity activity of soccer players in top-level competition. In: T. Reilly, \& Korkusuz, F, (Eds.) Science \& Football VI, (pp. 182-186). Abingdon, UK: Routledge. 


\section{Tables.}

Table I: Comparison of distances covered at different intensities in a reference team against three opposition team formations.

\begin{tabular}{|c|c|c|c|c|c|c|c|c|}
\hline \multirow[b]{2}{*}{ Position } & \multicolumn{8}{|c|}{ Distances covered $(\mathrm{m})$ at different movement intensities } \\
\hline & $\begin{array}{l}433 / 451 \\
\text { Versus }\end{array}$ & $\begin{array}{l}\text { Low/Moderate } \\
(0-14.3 \mathrm{~km} / \mathrm{h})\end{array}$ & $\begin{array}{l}\text { High } \\
(14.4-19.7 \mathrm{~km} / \mathrm{h})\end{array}$ & $\begin{array}{l}\text { Very high } \\
(\geq 19.8 \mathrm{~km} / \mathrm{h})\end{array}$ & $\begin{array}{l}\text { Total } \\
\text { Distance }\end{array}$ & $\begin{array}{l}\text { Total } \geq 14.4 \mathrm{~km} / \mathrm{h} \text { in } \\
\text { Individual Possession }\end{array}$ & $\begin{array}{l}\text { Total } \geq 14.4 \mathrm{~km} / \mathrm{h} \\
\text { Team in Possession }\end{array}$ & $\begin{array}{l}\text { Total } \geq 14.4 \mathrm{~km} / \mathrm{h} \\
\text { Team out of Possession }\end{array}$ \\
\hline Fullback & 442 & $8270 \pm 260$ & $1542 \pm 279$ & $843 \pm 128$ & $10655 \pm 497$ & $97 \pm 53$ & $965 \pm 281$ & $1222 \pm 179$ \\
\hline Fullback & $433 / 451$ & $8323 \pm 292$ & $1590 \pm 207$ & $911 \pm 153$ & $10824 \pm 473$ & $96 \pm 48$ & $1002 \pm 182$ & $1289 \pm 243$ \\
\hline Fullback & 4231 & $8404 \pm 334$ & $1592 \pm 266$ & $848 \pm 158$ & $10844 \pm 513$ & $86 \pm 36$ & $916 \pm 183$ & $1308 \pm 225$ \\
\hline Centre-half & 442 & $8246 \pm 348$ & $1288 \pm 177$ & $470 \pm 108$ & $10004 \pm 469$ & $77 \pm 43$ & $471 \pm 135$ & $1017 \pm 97$ \\
\hline Centre-half & $433 / 451$ & $8414 \pm 247$ & $1269 \pm 191$ & $477 \pm 112$ & $10161 \pm 404$ & $79 \pm 45$ & $480 \pm 124$ & $1021 \pm 168$ \\
\hline Centre-half & 4231 & $8431 \pm 325$ & $1264 \pm 185$ & $497 \pm 141$ & $10192 \pm 466$ & $69 \pm 51$ & $430 \pm 119$ & $1061 \pm 234$ \\
\hline Central-midfielder & 442 & $8518 \pm 267$ & $2001 \pm 297$ & $658 \pm 151$ & $11177 \pm 549$ & $99 \pm 61$ & $1172 \pm 336$ & $1343 \pm 293$ \\
\hline Central-midfielder & $433 / 451$ & $8545 \pm 228$ & $2029 \pm 319$ & $704 \pm 188$ & $11278 \pm 446$ & $95 \pm 48$ & $1098 \pm 316$ & $1466 \pm 291$ \\
\hline Central-midfielder & 4231 & $8587 \pm 263$ & $1985 \pm 308$ & $678 \pm 195$ & $11250 \pm 510$ & $99 \pm 69$ & $1051 \pm 387$ & $1430 \pm 233$ \\
\hline Wide-midfielder & 442 & $8221 \pm 410$ & $1478 \pm 270$ & $844 \pm 260$ & $10543 \pm 656$ & $202 \pm 47$ & $1537 \pm 279$ & $652 \pm 223$ \\
\hline Wide-midfielder & $433 / 451$ & $8413 \pm 426$ & $1633 \pm 236$ & $869 \pm 201$ & $10916 \pm 546$ & $157 \pm 66$ & $1372 \pm 254$ & $915 \pm 184$ \\
\hline Wide-midfielder & 4231 & $8495 \pm 480$ & $1591 \pm 263$ & $861 \pm 174$ & $10948 \pm 650$ & $168 \pm 70$ & $1336 \pm 231$ & $905 \pm 267$ \\
\hline Mean all positions & 442 & $8314 \pm 329$ & $1577 \pm 373$ & $704 \pm 219$ & $10594 \pm 681$ & $119 \pm 65$ & $1036 \pm 448^{\star \star *}$ & $1058 \pm 307$ \\
\hline Mean all positions & $433 / 451$ & $8424 \pm 301$ & $1630 \pm 376$ & $741 \pm 236$ & $10795 \pm 624$ & $107 \pm 57$ & $988 \pm 392$ & $1172 \pm 314^{\star * \star *}$ \\
\hline Mean all positions & 4231 & $8479 \pm 350^{\star *}$ & $1608 \pm 374$ & $721 \pm 222$ & $10808 \pm 661^{*}$ & $106 \pm 67$ & $933 \pm 409$ & $1176 \pm 310^{\star * * *}$ \\
\hline
\end{tabular}

* Significantly more distance covered against 4-2-3-1 compared to 4-4-2 formations $(\mathrm{p}<0.05)$

** Significantly more distance covered against 4-2-3-1 compared to 4-4-2 formations $(\mathrm{p}<0.01)$

*** Significantly more distance covered against 4-4-2 compared to 4-2-3-1 formations $(\mathrm{p}<0.05)$

**** Significantly more distance covered against 4-3-3/4-5-1 ( $<<0.05)$ and 4-2-3-1 (p<0.01) compared to 4-4-2 formation 
Table II: Characteristics of total high-intensity performance $(\geq 14.4 \mathrm{~km} / \mathrm{h})$ in a reference team against three different opposition team formations.

\begin{tabular}{|c|c|c|c|c|c|c|c|c|c|}
\hline \multirow{3}{*}{ Position } & \multicolumn{9}{|c|}{ Total High-intensity Performance $(\geq 14.4 \mathrm{~km} / \mathrm{h})$} \\
\hline & \multirow{2}{*}{$\begin{array}{l}433 / 451 \\
\text { Versus }\end{array}$} & \multicolumn{3}{|c|}{ Recovery time (s) } & \multicolumn{3}{|c|}{ Length $(\mathrm{m})$} & \multicolumn{2}{|c|}{ Performance decrement (\%) } \\
\hline & & 1 Half & 2 Half & Mean & 1 Half & 2 Half & Mean & 1 st vs End $15 \mathrm{mins}$ & Mean vs End $15 \mathrm{mins}$ \\
\hline Fullback & 442 & $26.8 \pm 5.2$ & $29.0 \pm 4.8$ & $27.9 \pm 4.0$ & $13.1 \pm .07$ & $13.1 \pm 1.3$ & $13.1 \pm 0.6$ & $15.3 \pm 26.7$ & $6.2 \pm 26.8$ \\
\hline Fullback & 4231 & $25.5 \pm 4.5$ & $27.8 \pm 4.3$ & $26.7 \pm 3.6$ & $13.0 \pm 0.8$ & $12.7 \pm 0.9$ & $12.8 \pm 0.7$ & $7.0 \pm 34.7$ & $3.1 \pm 22.5$ \\
\hline Centre-half & 442 & $36.4 \pm 5.9$ & $38.8 \pm 6.7$ & $37.6 \pm 5.3$ & $12.6 \pm 1.1$ & $13.0 \pm 1.5$ & $12.8 \pm 1.2$ & $12 \pm 23.7$ & $0.2 \pm 25.8$ \\
\hline Centre-half & 433 & $35.3 \pm 5.4$ & $38.4 \pm 6.7$ & $36.8 \pm 4.6$ & $12.3 \pm 1.2$ & $12.4 \pm 1.1$ & $12.4 \pm .9$ & $18.0 \pm 25.0$ & $8.2 \pm 24.9$ \\
\hline Central-midfielder & 433 & $22.2 \pm 4.1$ & $24.3 \pm 4.5$ & $23.2 \pm 3.9$ & $12.6 \pm 0.9$ & $12.7 \pm 0.9$ & $12.6 \pm 0.8$ & $6.2 \pm 43.3$ & $10.2 \pm 22.8$ \\
\hline Central-midfielder & 4231 & $24.0 \pm 4.9$ & $25.2 \pm 5.1$ & $24.6 \pm 4.1$ & $12.9 \pm 0.8$ & $13.0 \pm 1.01$ & $12.9 \pm 0.7$ & $7.0 \pm 36.7$ & $6.8 \pm 25.0$ \\
\hline Wide-midfielder & 442 & $28.2 \pm 5.1$ & $29.3 \pm 6.5$ & $28.7 \pm 5.3$ & $13.5 \pm 0.6$ & $12.6 \pm 0.8$ & $13.0 \pm 0.6$ & $18.9 \pm 18.3$ & $12.2 \pm 23.8$ \\
\hline Wide-midfielder & 433 & $26.0 \pm 3.7$ & $28.0 \pm 4.8$ & $27.0 \pm 2.8$ & $13.1 \pm 1.1$ & $13.8 \pm 1.1$ & $13.4 \pm 0.9$ & $4.5 \pm 31.6$ & $3.7 \pm 22.1$ \\
\hline Wide-midfielder & 4231 & $27.6 \pm 6.1$ & $27.7 \pm 3.2$ & $27.6 \pm 3.8$ & $13.6 \pm 0.9$ & $13.0 \pm 1.1$ & $13.3 \pm 0.7$ & $12.3 \pm 37.7$ & $10.8 \pm 34.3$ \\
\hline
\end{tabular}

$1^{\text {st }}$ vs. End 15 mins: Distance covered in the $1^{\text {st }} 15 \min$ period versus that covered in the final 15 -minute period

Mean vs. End 15mins: Distance for the mean of all 15min periods (minus final period) versus that covered in the final 15-minute period 
Table III: Comparison of skill-related performance in a reference team against three opposition team formations.

\begin{tabular}{|c|c|c|c|c|c|c|c|c|c|c|}
\hline $\begin{array}{l}\text { Playing } \\
\text { Position }\end{array}$ & $\begin{array}{l}433 / 451 \\
\text { Versus }\end{array}$ & $\begin{array}{c}\mathrm{N}^{\circ} \\
\text { Passes }\end{array}$ & $\begin{array}{c}\text { № Forward } \\
\text { Passes }\end{array}$ & $\begin{array}{l}\text { Mean pass } \\
\text { distance }(m)\end{array}$ & $\begin{array}{l}\text { \% 1-touch } \\
\text { Passes }\end{array}$ & $\begin{array}{l}\mathrm{N}^{\circ} \text { Individual } \\
\text { possessions }\end{array}$ & $\begin{array}{l}\text { Mean touches } \\
\text { per possession }\end{array}$ & $\begin{array}{l}\text { Mean time per } \\
\text { possession (s) }\end{array}$ & $\begin{array}{l}\text { № Ground } \\
\text { Duels }\end{array}$ & $\begin{array}{l}\mathrm{N}^{\circ} \text { Aerial } \\
\text { Duels }\end{array}$ \\
\hline Fullback & 442 & $53.1 \pm 12.3$ & $38.9 \pm 8.4$ & $19.6 \pm 2.5$ & $49.7 \pm 12.4$ & $57.1 \pm 12.2$ & $1.8 \pm 0.3$ & $0.9 \pm 39$ & $6.7 \pm 2.4$ & $4.7 \pm 2.5$ \\
\hline Fullback & $433 / 451$ & $53.8 \pm 16.6$ & $41.3 \pm 11.4$ & $19.2 \pm 3.4$ & $49.5 \pm 12.7$ & $57.8 \pm 17.1$ & $1.8 \pm 0.3$ & $1.0 \pm 0.3$ & $7.0 \pm 3.4$ & $4.3 \pm 1.7$ \\
\hline Fullback & 4231 & $49.5 \pm 12.0$ & $38.7 \pm 9.8$ & $19.0 \pm 2.9$ & $52.6 \pm 11.8$ & $53.6 \pm 11.8$ & $1.8 \pm 0.3$ & $1.0 \pm 0.3$ & $7.6 \pm 3.2$ & $4.8 \pm 3.5$ \\
\hline Centre-half & 442 & $44.1 \pm 11.2$ & $35.4 \pm 10.6$ & $22.4 \pm 2.1$ & $37.9 \pm 8.6$ & $44.2 \pm 15.0$ & $2.1 \pm 0.3$ & $1.3 \pm 0.4$ & $3.7 \pm 2.1$ & $5.9 \pm 2.8$ \\
\hline Centre-half & $433 / 451$ & $39.7 \pm 9.4$ & $31.8 \pm 7.2$ & $24.0 \pm 3.1$ & $40.6 \pm 9.5$ & $41.0 \pm 9.6$ & $1.9 \pm 0.3$ & $1.2 \pm 0.4$ & $4.3 \pm 2.3$ & $6.8 \pm 3.3$ \\
\hline Centre-half & 4231 & $37.1 \pm 10.7$ & $30.6 \pm 8.5$ & $24.4 \pm 3.7$ & $45.8 \pm 9.7$ & $39.2 \pm 11.4$ & $1.9 \pm 0.2$ & $1.1 \pm 0.3$ & $4.5 \pm 3.3$ & $7.2 \pm 4.1$ \\
\hline Central-midfielder & 442 & $56.2 \pm 13.8$ & $35.6 \pm 10.2$ & $23.3 \pm 15.6 \#$ & $34.9 \pm 11.6$ & $57.9 \pm 17.5$ & $2.1 \pm 0.3$ & $1.0 \pm 0.3$ & $6.6 \pm 3.0$ & $1.7 \pm 1.0$ \\
\hline Central-midfielder & $433 / 451$ & $49.0 \pm 16.6$ & $31.8 \pm 11.4$ & $18.7 \pm 3.4$ & $33.8 \pm 12.6$ & $53.9 \pm 17.1$ & $2.1 \pm 0.3$ & $1.1 \pm 0.3$ & $7.9 \pm 3.4$ & $2.1 \pm 1.7$ \\
\hline Central-midfielder & 4231 & $45.1 \pm 11.8$ & $29.1 \pm 8.0$ & $18.1 \pm 3.2$ & $36.7 \pm 9.8$ & $51.4 \pm 13.2$ & $2.1 \pm 0.3$ & $1.1 \pm 0.3$ & $8.9 \pm 4.9$ & $3.9 \pm 2.9$ \\
\hline Wide-midfielder & 442 & $42.7 \pm 13.1$ & $23.8 \pm 9.6$ & $17.4 \pm 5.2$ & $27.3 \pm 8.2$ & $54.9 \pm 11.9$ & $2.7 \pm 0.7$ & $1.6 \pm 0.4$ & $7.3 \pm 2.5$ & $2.1 \pm 0.8$ \\
\hline Wide-midfielder & $433 / 451$ & $43.3 \pm 11.8$ & $25.6 \pm 7.9$ & $19.4 \pm 2.9$ & $34.0 \pm 9.1$ & $52.4 \pm 11.7$ & $2.2 \pm 0.3$ & $1.3 \pm 0.4$ & $8.8 \pm 4.9$ & $3.9 \pm 2.9$ \\
\hline Wide-midfielder & 4231 & $41.0 \pm 8.8$ & $24.8 \pm 9.1$ & $19.8 \pm 4.4$ & $38.5 \pm 10.5$ & $52.1 \pm 8.6$ & $2.3 \pm 0.4$ & $1.3 \pm 0.4$ & $9.6 \pm 4.6$ & $4.6 \pm 2.9$ \\
\hline Mean all positions & 442 & $49.0 \pm 13.4^{*}$ & $33.4 \pm 10.7$ & $20.7 \pm 8.6$ & $37.5 \pm 12.9$ & $53.5 \pm 15.4$ & $2.2 \pm 0.5^{\star \star}$ & $1.2 \pm 0.4$ & $6.1 \pm 2.8$ & $3.6 \pm 2.7$ \\
\hline Mean all positions & $433 / 451$ & $46.4 \pm 13.7$ & $32.6 \pm 10.3$ & $20.3 \pm 3.8$ & $39.5 \pm 11.7$ & $51.3 \pm 14.4$ & $2.0 \pm 0.3$ & $1.2 \pm 0.3$ & $7.0 \pm 3.8$ & $4.3 \pm 3.1$ \\
\hline Mean all positions & 4231 & $43.2 \pm 11.9$ & $30.8 \pm 9.9$ & $20.3 \pm 4.3$ & $44.7 \pm 11.6^{\star \star \star \star}$ & $49.0 \pm 12.9$ & $2.0 \pm 0.3$ & $1.1 \pm 0.3$ & $7.7 \pm 4.5^{\star \star \star}$ & $5.1 \pm 3.6^{\star \star *}$ \\
\hline
\end{tabular}

* Significantly more passes versus a 4-4-2 compared to a 4-2-3-1 $(\mathrm{p}<0.01)$

** Significantly more touches per possession versus a 4-4-2 than a 4-2-3-1 (p<0.01) and a 4-3-3 (p<0.01)

$* * *$ Significantly more duels against a 4-2-3-1 than a 4-4-2 ( $<<0.01)$

**** Significantly larger percentage of 1-touch passes versus a 4-2-3-1 than a 4-4-2 (p<0.001) and 4-3-3 (p<0.05)

\# Mean pass distance significantly greater in central-midfielders versus a 4-4-2 compared to a 4-3-3/4-5-1 (p<0.05) and 4-2-3-1 (p<0.01) 